\title{
GARANTIAS JURÍDICAS QUE PROTEGEM A PROPRIEDADE NAS DESAPROPRIAÇÕES *
}

\section{MANOEL DE OLIVEIRA FRANCO SOBRINHO}

Examinando o instituto das desapropriações, nas perspectivas históricas e nas suas tendências atuais, observamos que os lineamentos jurídicos fundamentais continuam sempre os mesmos. Na verdade quase nada se alterou que tornassem inexistentes as fontes romanas. Ou que transformasse a natureza tradicional do importante instituto. Se algo diferente aconteceu resultou de imperativas condições sociais qualificando funções e determinando finalidades.

Todavia, embora sistemas e legislações, a fonte romana ainda se faz viva, já que, em face da realidade do tempo, as sociedades procuram manter o equilíbrio natural entre o público e o privado, entre o social e o particular, entre o Estado-poder e o homem-direitos. Transmitindo valores estáveis, o direito romano transmitiu, em toda sua pureza, instrumentos que assentam em regimes de garantias jurídicas, em sistemas que protegem bens do possível discricionarismo estatal.

Dois enfoques chegam das origens romanas: o da Administração submetida ao direito e não à sua própria vontade; o da vontade administrativa no ato de expropriar não exceder o devido processo legal. Os avanços do poder estatal, nas áreas privadas atingindo a propriedade, um direito natural seja qual for sua expressão, possuem limites que impedem de agir através excessos, para somente agir motivado pela necessidade, utilidade ou interesse exatamente figurados.

Atendendo, por isso, as chamadas prerrogativas públicas ou as chamadas garantias jurídicas, temos entre elas um vínculo natural assistido pelo direito. Impondo que a necessidade venha

* Palestra proferida, a convite do Departamento de Direito, da Universidade Católica de Minas Gerais, no Seminário Sobre Desapropriação, na 2.a quinzena de abri! de 1982 . 
apontada, que a utilidade esteja prevista ou que o interesse chegue concreto. Diante de leis maiores e da natureza das coisas, cabe dizer o que seja necessidade, utilidade ou interesse, conceitos ligados porque não abstratos à legitimidade e à responsabilidade.

Todos nós, um a um dos aqui presentes, temos direitos naturais e jurídicos ao mesmo tempo. A casa que é nossa em que moramos, o relógio que usamos amarrado ao pulso, as coisas que desfrutamos, os valores que possuimos, não podem ficar sujeitos a uma lei que faça objeto da desapropriação todos os bens convenientes à satisfação pública, qualquer seja a nature$\mathrm{za}$, sejam quais forem as posses privadas.

\section{PRESSUPOSTOS ARBITRÁRIOS DIANTE DO OBJETO}

Tomba no arbítrio administrativo, qualquer diploma expropriatório, que não determine exemplarmente os casos de expropriação. Razão pela qual, num país como a Argentina, condenamos a lei n. ${ }^{\circ} 21.499$, de 17 de janeiro de 1977, estendendo o poder de expropriar sem discriminar casos de necessidade, de utilidade ou de interesse, deixando livre a Administração para decidir sobre o destino de bens particulares.

No Brasil, pelo menos até agora, à partir da lei de 1826, tivemos diplomas altamente valiosos pela objetividade na aplicação do mandamento constitucional. Tanto o de 1836 como o de 1845 marcam etapas de aguda sensibilidade jurídica. Inclusive nas regulamentações, como a de 1903, a necessidade vem programada tal como também a utilidade. Tudo para colocar a Administração no limite do seu poder e assegurar ao administrado o gozo dos seus direitos.

Vejo, no decreto-lei n. ${ }^{\circ} 3.365$, de 1941 , diploma até certo ponto insubstituível nos seus propósitos. Não tão objetivo quanto ao contido na legislação anterior, isto porque não separa a necessidade da utilidade, mas exemplar no tocante aos casos capitulados no art. $5 .^{\circ}$. Compete à lei, não à Administração, dizer do poder de expropriar, evitando que na subjetividade falha de critérios, violentam-se direitos naturais constitucionalmente protegidos.

A sistemática, no Brasil, sempre tem sido boa, para não dizer excelente. Querem exemplo? O da lei n. 4.132 , de 1962, definindo os casos de interesse social. Do que precisamos hoje 
é de uma consolidação da legislação expropriatória, dando unidade, racionalizando, atualizando preceitos, fugindo o quanto possível de faculdades que permitam à Administração exceder-se ou desviar-se dos ditames constitucionais. A questão, a propor, tem sede no aperfeiçoamento das normas aplicáveis.

O que vem a ser pois desapropriação? Esta deveria ser. num encontro de estudos como este, a indagação inicial. Com uma resposta, fazendo compreender que, a atuação expropriatória, tipo de legítima intervenção pública, destina-se retirar a propriedade de bens dos particulares, porém conforme o ordenamento normativo, dentro de justos princípios motivantes, razões finalísticas, implicações procedimentais obrigatórias e imediatas reparações econômicas.

\section{LEGITIMIDADE EXPROPRIATÓRIA}

Afetando o que a pessoa humana tem de mais sagrado, bens incorporados ao patrimônio personificado, a propriedade no sentido fisiológico, a desapropriação como maneira legal de intervenção pública, não desconhece que a eficácia do ato administrativo a projetar-se requer além do fundamento constitucional, motivos ajustados aos casos, cumprimento de regras sem as quais perde conteúdo de legitimidade.

As facilidades administrativas, ocorrentes entre nós, com o beneplacito da devida tutela jurisdicional, levando pela demora à medidas corretivas, chegam para demonstrar que na maioria das ações propostas, a vontade declarada de expropriar não vêm manifestada na legitimidade, pois ab initio a intenção de não pagar o justo-preço constitui verdadeira distorção das relações jurídicas criadas.

Decorre, a legitimidade expropriatória, de alguns pressupostos, tais como: respeito ao mandamento constitucional, obediência à norma especifica, exação na prática do ato declaratório, motivação que dê conteúdo ao ato, indicação do caso permitido por lei, prevenção de recursos próprios à transferência forçada da propriedade, processo administrativo ou judicial amparando direitos postos em conflito.

Aí é que se colocam as garantias jurídicas que protegem a propriedade nas desapropriações. Havendo acordo a declaração passa a simples forma de compra e venda. Não havendo fica em exame a aplicação do mandamento constitucional, a nor- 
ma que ofereça suporte ao ato, o caso que dá motivo à vontade, o preço oferecido em consonância com o valor econômico da coisa a expropriar.

Ninguém tira nada de ninguém a não ser em virtude de lei. $\mathrm{Na}$ base de qualquer ato administrativo, sobretudo nos de declaração expropriatória, está a norma legal permissiva, imperativa quanto à vontade das partes, determinante quanto aos efeitos jurídicos. Ganhando importância ou realce o exame pelo hermeneuta e na jurisdição do ato em execução nos aspectos de legalidade subjetiva e objetiva.

\section{EXCESSO NO PODER DE EXPROPRIAR}

Inscrevem-se as garantias jurídicas, não prosperando o acordo entre partes, primeiro no fundamento constitucional e nas leis que dele promanam, depois nos motivos que levaram ao ato expropriatório. A finalidade, a atingir, ou atingida, não pode desfigurar-se, nem desqualificar-se. Não será preciso lembrar, que tanto nos acordos como nas decisões judiciais, a vontade vem ligada à finalidade expropriatória.

$\mathrm{O}$ ato expropriatório, tendo na finalidade expropriatória, a sua razão de ser jurídica fundamental, há de harmonizar a vontade com a lei para produzir os devidos efeitos jurídicos. Se a lei diz, em face da indispensável motivação, quais os casos de desapropriação, os excessos ou abusos desafiam a proteção jurisdicional, ficando reparatoriamente avaliáveis no plano indenizatório por perdas e danos.

Do equilíbrio da relação jurídica estabelecida por força de lei entre expropriante e expropriados, necessariamente dependem os resultados expropriatórios. Fixado um caso, inserto no ato, nada pode ir além do objetivado. A coisa, em sí, no seu valor patrimonial, não vindo definida in concreto ou figurada nos contornos, ilegitima a declaração pela imprecisão do querer ou inadequação legal.

A lisura de comportamento administrativo ou na conduta expropriatória, constitui fator originário a fim do ato de vontade não desaguar na ilegitimidade. O excesso no pedido traduz infringência legal, embora alguns achem que a declaração não admite exame jurídico, assim não acho porque as prerrogativas públicas não trazem o condão de anular as garantias dos administrados. 
O poder de expropriar, não é um poder ilimitado, mas um poder limitado às condições previstas em lei. A necessidade que há de ser apontada, a utilidade que exige figuração, o interesse social que tem de ser social na expressão do postulado, fazem condições imperativas. Não podendo conter a declaração, portanto, excessos que devem ser denunciados ou desvios desnaturando o espírito da lei.

\section{DESVIO NO PODER DE EXPROPRIAR}

O desvio, nas desapropriações, diz respeito à finalidade. Não existe, um só ato administrativo, ou um só ato expropriatório, que não traga uma finalidade obetiva. $O$ interesse público, embora escudado no conceito de serviço, não justifica o uso do poder de expropriar fora exatas determinações legais. Repugna a ordem jurídica a tomada de bens particulares para efeitos mercantís impróprios.

Também os códigos civis, à maneira do brasileiro no art. 590 , cuidando de desapropriação, quando falam de perda da propriedade, considerem os casos específicos de necessidade pública ou de utilidade pública. A nomeação dos casos, além de virtualizarem garantias jurídicas, diante da intenção-vontade e do ato conseqüênte, visa sem dúvida impedir excessos ou desvio de finaliłade.

A tradição é boa e no meu entender deve ser mantida, não obstante em face dos serviços públicos a serem prestados, possam os casos ser ampliados para atender no interesse administrativo o que a Administração possa querer, mas querer na legitimidade, longe de excessos ou desvios que afetem direitos do administrado. Não é demais dizer da sabedoria dos códigos civis.

Nos institutos afins, apreciados rapidamente, prevalecem as mesmas garantias jurídicas. $\mathrm{Na}$ ocupação temporária, equivalente ao arrendamento forçado, o valor da propriedade fica indiscutível. Na requisição, onde se envolvem bens, móveis, semoventes ou serviços, os valores permanecem atuais, resguardados in tempore pela não exclusão da competência contenciosa nas hipóteses de excessos ou desvios.

Vinga aqui o histórico instituto da retrocessão, infelizmente esquecido no decreto-lei n. 3.365 . 0 caráter forçado da transferência de bens, a imposição alienatória jamais considerada uma coação material, no ordenamento jurídico não surgem di- 
vorciadas das garantias asseguradas. Nada mais correto que, atendendo vínculo existente na relação jurídica, o Estado não proceda preterindo o essencial.

\section{A IMPORTÂNCIA DA RETROCESSÃO}

Aplicado o princípio da finalidade aos eventuais prejuizos causados pela Administração, na verdade os prejudicados para a defesa de interesses dignos de proteção administrativa ou judicial, ficam com o direito de pleitar o retorno dos bens sacrificados, já que de resto é o próprio expropriante que está a dizer da desmotivação expropriatória desfiguradora do instituto.

A retrocessão dos bens ou dos direitos ao primitivo titular, embora possa não ter caráter punitivo ou não apontar danos maiores, constitui com respeito às coisas corpóreas ou com respeito a certos direitos privados, responsabilidade administrativa objetiva. Alargando a responsabilização em face da desqualificação do interesse público e sem que precise determinar o fato ilicito ou a culpa.

Simplesmente, desviada a finalidade, confessada a intenção real do desvio, portanto caracterizada a desapropriação irregular, uma vez não aproveitada a coisa expropriada conforme destinação prevista, responde o Estado diante do apoderamento indevido, pois atuando de maneira prejudicial atentou contra princípio ordenativo constitucional. A retrocessão, passa assim, a uma garantia jurídica da propriedade.

Corolário do preceito constitucional relativo à propriedade, a retrocessão como garantia jurídica da reversão do bem expropriado, repondo direitos coloca o primitivo titular no uso e goso do que se lhe tirou, caracterizando restituição nas hipóteses de burla à vontade do legislador, de má aplicação da lei pertinente, de infração de uma norma imperativa na ordem expropriatória.

Não é aqui o quantum econômico que está em jogo, nem os danos pelo despojamento da propriedade, mas uma reparação que não se limita ao preço da coisa, mantém inalterado o direito do administrado, promovendo litis capaz diante do desapossamento, de repor a coisa na antiga situação jurídica, de restaurar ante o desvio de finalidade, a garantia jurídica suprimida pela desapropriação. 


\section{GARANTIAS NA PAUTA DOS DIREITOS}

Onde se colocam as garantias jurídicas protetoras em face da disforme atividade expropriatória? $\mathrm{O}$ que representam, na ordem jurídica constitucional e positiva, para o administrado? Não é difícil enumerá-las observando o que vem da lei, dos fatos e dos atos declaratórios sujeitos à necessidade, à utilidade púses de burla à vontade do legislador, de má aplicação da lei blica ou ao interesse social. Principalmente do ato quando se opõe:

- ao rigor imperativo do mandamento constitucional;

- à competência jurídica nas esferas administrativas jurisdicionais;

- aos casos exemplarmente apontados;

— à detenminação figurada do objeto certo a expropriar;

- ao justo-preço previamente estabelecido ou oferecido;

— à norma na sua existência objetiva;

- ao direito na sua existência subjetiva;

- ao procedimento instrumental interno e no plano judicial;

- à forma da norma como imperativo de força obrigatória;

- às conseqüências jurídicas inseparáveis de outros direitos conéxos.

Numa rápida análise conjuntural, muito importa ao direito expropriatório, ao fundamentar a vontade de intervir na propriedade privada, respeitar na licitude dos propósitos tudo quanto diga com a projeção do ato na largueza dos efeitos jurídicos. Já que toda norma possuindo uma forma e um conteúdo, ao ganhar eficácia compromete a Administração, não se legitimando senão através de conduta ajustada à finalidade.

A experiência, pelo menos no Brasil, demonstra à sobejo, que só a vontade expropriatória não basta, porque tem levado a Administração à numerosas ações onerosas, pois a demora 
nos acordos ou nas soluções finais, conduz a corretivos econômicos imprevistos, porém geradores de responsabilịdade. A questão tem capital importância diante das facilidades com que aqui se fabricam atos declaratórios.

\section{GARANTIAS NAS LESÕES CONTINUADAS}

Nos regimes constitucionais, onde a regulação da conduta administrativa seja estável, as várias espécies de normas cumprem uma função especial. Uma função especificada tal como nas desapropriações permitidas. Cabendo ao Estado, através da Administração, em virtude das garantias asseguradas, quando tomar a iniciativa, tomá-la em termos que evitem lesões progressivas ou continuadas.

Ademais, nos sistemas jurídicos de fins, como nos regimes procedimentais expropriatórios, as garantias vão além do interesse jurídico para alcançarem o interesse econômico ou material. Quando os fins na ordem pública refletem nas situações privadas, fique claro que a Administração não deve chegar a extremos, porque abandonando reservas ou limitações, cria situações que pedem garantias.

Três elementos, na relação jurídica expropriatória, quer administrativa ou judicial, devem sem dúvida nos regimes de garantias jurídicas integrar as leis na matéria, igualando as partes nas postulações, identificando as pessoas conforme a finalidade pública, atendendo a reciprocidade na justaposição de interesses legítimos, harmonizando contrários pela força dos fins. E que são estes:

- o das prerrogativas estatais;

- o das normas disciplinadoras;

- o das garantias dos administrados.

As prerrogativas, embora assentadas em poderes funcionais, nascendo do próprio instituto da desapropriação, não excedem interesses jurídicos transcendentes. Dão ao Estado nos casos expropriatórios capacidade na competência para privar alguém da sua propriedade, mas não possuem na essência caráter prejudicial bastante para alterar situações sem responder pela supressão de bens particulares.

As prerrogativas administrativas manifestam-se no momen- 
to em que a Administração decide expropriar. Desaparecem uma vez tomada a iniciativa patrimonial, são direitos que só se extinguem com a translação definitiva e o cumprimento na extensão das obrigações assumidas, dispostas em lei e por lei definidas.

\section{IMPORTÂNCIA DOS CASOS EXEMPLIFICADOS}

Entendendo por sistema legal, o conjunto de elementos relacionados entre si de feição coerente, a reunião de princípios coordenados de maneira a formar um corpo de doutrina, a combinação de partes para um mesmo resultado, nada mais que isto queremos no tocante à leis que envolvam complexos institutos jurídicos nos quais os objetivos disciplinadores enquadram permissividade, direitos e garantias.

Sabendo porém que os sistemas dependem dos regimes, do ato ou efeito de reger, de direção ou formas, de vontade nos modos de proceder, faz preciso que a lei expropriatória ao ser administrada assente num sistema de normas gerais relativas a objetos determinados, ou seja, num elenco de prescrições qualitativas e quantitativas concernentes ao exercício das prerrogativas públicas.

Voltando a uma saudável tradição e procurando conhecer exigências públicas atuais, não podemos deixar de destacar a importância dos casos exatamente exemplificados. A experiência, sem dúvida, fala mais alto que as boas intenções legislativas. Recomenda que as leis, na aplicabilidade, sejam pensadas considerando fatos, atos e meios, sobretudo distinguindo pelo objeto até onde pode ir o poder administrativo.

Se me fosse dado, num determinado regime montar um sistema expropriatório, os casos no meu entender viriam distribuidos conforme o relevo da finalidade, de acordo com o objeto da permitida vontade administrativa, colocando a Administração nas circunstâncias fáticas, capaz de proceder com eficiência, diante:

— da necessidade pública;

— da utilidade pública;

- do interesse social.

Pois bem, definida a necessidade teríamos, os casos: defesa do Estado, segurança nacional, calamidades públicas; apontada a utilidade, os casos: edifícios públicos, transportes, rodo- 
vias; qualificado o interesse social, os casos: habitação, terras, bem-estar coletivo. Claro que as indicações não esgotam demais situações a nominar. Servem apenas para esclarecer uma posição exegética de pensamento.

\section{O QUE NOVA LEI DEVE REFORMULAR}

Cogitando-se de nova lei jurídico-instrumental, qualquer proposta ao Legislativo, visando estabelecer maior equilíbrio entre os poderes do expropriante e os direitos do expropriado, em substituição aos hábeis diplomas existentes, deve através de linhas de conduta administrativa e processual, refletir simplicidade textual, redução de prazos, validade do ato declaratório conforme disposições regradas.

Há fatores incidentes, nascidos dos desajustes econômicos, que a fim não produzirem distorções mandamentais, requerem obediência para que 0 ato tome legitimidade, como os que ferem a prévia e justa indenização, de acordo com a determinação constitucional. Valorando o processo administrativo anterior à declaração, tão somente porque a Administração na sua vontade sabe das suas prerrogativas e o que pode fazer.

A exceção, no caso de imóveis rurais, quando a indenização poderá ser feita em títulos especiais da dívida pública, desde que fica com a lei estabelecer os critérios, sem prejuízo de exata correção monetária e do resgate, não inibe que se cumpra no momento do pedido expropriatório, o pagamento justo e prévio da indenização segundo o princípio determinante hierárquicamente superior.

Como o Estado, poder responsável, não deve brincar com a necessidade pública, com a utilidade ou o interesse social, o problema da desistência nas desapropriações, já que não se discute o caráter próprio de ação, só se torna viável antes da contestação e na base da lei processual civil, sujeitando-se o expropriante à indenização dos prejuízos causados com o desapossamento imissório.

Por outro lado, dar só ao Executivo poder de expropriar, tirando a competência do Legislativo e do Judiciário, não é a melhor maneira de harmonizar os poderes. A questão, quando bem enfocada, é de jurisdição, de orçamento próprio, de previsão de recursos e de vontade legitimada, não havendo porque distinguir prerrogativas quando se atribuem múnus às entidades autárquicas ou paraestatais. 


\section{PONTOS FINAIS}

Tão largos ficam os aspectos de necessidade pública, de utilidade ou interesse social, que em face das garantias jurídicas que protegem a propriedade nas desapropriações, é preciso que o legislador antes de mais nada considere o sentido econômico da intervenção no patrimônio particular. Não basta um ato, uma declaração, porque o importante tem suporte na permitida figuração expropriatória.

Vejam bem o que está em ịogo: imóveis, trabalhos científicos, ações, propriedade industrial, fundo de comércio, riquezas naturais, áreas urbanas ou urbanizáveis, o sub-solo e o espaço aéreo, o capital das organizações privadas, direitos autorais ou invenções, quotas societárias, bens comunitários, preocupando sobretudo após imissão a destinação que se possa dar às afetadas.

Não raras vezes está em apreciação a moralidade administrativa, a exação no comportamento administrativo, criando desigualdades na oferta-preço, a vontade laborando intenção que refoge das causas determinantes, a imprecisão da motivação tornando duvidosa a declaração. Deixando com isso, em suspenso, se na verdade há ou não necessidade, utilidade ou interesse, diante do objeto jurídico.

Sabemos, ser nada fácil, a perfeição de um diploma legal. Diploma que harmonize, em face da finalidade, o querer com a legitimidade. Daí ressaltarmos a importância do devido processo administrativo e do controle jurisdicional. Contendo a Administração nos excessos ou desvios. Colocando a atividade administrativa à nível da legalidade. Resguardando garantias transformadas em direitos.

Valha a oportunidade quando renovamos estudos em torno do instituto expropriatório. Abrindo, como agora estamos, caminho às contribuições de experiência e conhecimento. De minha parte, pelo que deixo dito, uma lei só passa a boa, amplamente debatida. Sensibilizando no debate estudantes e professores. Dos mais belos institutos, o da desapropriação, merece façamos delo motivo de profunda preocupação. 